\title{
CFCs and Rising Global Temperature During 1969-1998: A Time Series Analysis
}

\author{
Partha Gangopadhyay ${ }^{1} \&$ Baljeet Singh ${ }^{2}$ \\ ${ }^{1}$ Business School, Western Sydney University, Australia \& School of Economics, University of the South Pacific, \\ Fiji
}

${ }^{2}$ School of Economics, University of the South Pacific, Fiji

Correspondence: Partha Gangopadhyay, Western Sydney University, Australia. E-mail: p.gangopadhyay@westernsydney.edu.au

Received: April 22, 2017

Accepted: May 4, 2017

Online Published: July 10, 2017

doi:10.5539/mas.v11n8p68

URL: https://doi.org/10.5539/mas.v11n8p68

\begin{abstract}
This paper seeks to assess if there is any evidence that Chlorofluorocarbons (CFCs) have caused global warming during 1969 to 1998 . The choice of the period of study is driven by the historical fact that the accumulation of CFCs in the atmosphere increased during this phase and the global temperature also registered steady increases. By exploiting a data set on accumulated CFCs along with changes in the global temperature we bring two new insights to the literature on global warming and CFCs: first and foremost, we introduce an Autoregressive Distributed Lagged (ARDL) model to capture the long-term relationship between CFCs and global warming. By doing this we establish that a statistically significant long-run relationship exists between CFCs and global warming. Secondly, we also establish that the nature of this relationship is rather counter-intuitive: the growth in the concentration of CFCs in the atmosphere, as our study finds, has reduced the increases in the global temperature during $1969-1998$. There is thus little empirical support that the CFCs are a source of global warming.
\end{abstract}

Keywords: ARDL model, CFCs, Cointegration, global warming

JEL Classifications: Q430, O530, P280

\section{Introduction}

In this paper we will side-step the debate that the work of Lu (2013) has created over the roles of Chlorofluorocarbons (CFCs) vis-à-vis non-CFCs gases in global warming (Note 1) In the existing literature the anthropogenic emission of non-CFC gases such as $\mathrm{CO} 2$ has been found the main cause behind global climate change and consequent global warming. Yet the work of $\mathrm{Lu}$ (2013), by analyzing the existing data, argues that the interaction CFCs with cosmic rays not only created the ozone holes but also global warming. In the existing literature many work showed that $\mathrm{CO} 2$ is the major anthropogenic source of environmental problems (see Zhang and Gangopadhyay, 2015; Zhang and Cheng, 2009; Wang et el., 2011; Tang, 2015; Tingvall and Ljungwall, 2012; Dong et el.; 2012; 2013a; 2013b; Chen, 2012; Chang, 2010 among many).

In this paper, we don't entertain the debate over CFCs or $\mathrm{CO} 2$. Nor we pay attention to the argument whether global temperature has really started rising at a slower rate after 2002. Instead we focus upon CFCs and utilize an extremely parsimonious model to unravel if there is any evidence that there exists a long-run relationship between CFCs and global warming during 1969 to 1998. In this work our focus is upon a historical time period spanning from 1969 to 1998 to understand if there is any time series evidence that the global warming in this period has been driven by a rising accumulation of CFCs. If we find no such evidence then our work establishes that non-CFCs gasses are the main anthropogenic sources of global warming (see the first paragraph of Section 2 and Note 2).

We also highlight the nature of this relationship in this paper. In what follows, we present our model, discuss the data and collate the results in Section 2 and conclude in Section 3.

\section{Basic Framework}

Since the 1750 s the $\mathrm{CO} 2$ in atmosphere has been rising steadily while the global temperature also accompanied the soaring levels of CO2 till 2002. According to Lu (2013), the CFCs also recorded their rising levels especially since 
1969 till 2002. Some will disagree with the end date as some argue that the concentration in CFCs in the atmosphere stopped its growth by the late 1990s. We thus choose our study period from 1969 to 1998 when accumulation CFCs displayed an upward trend. In his work, Lu noted a falling global temperature to match the falling level of CFCs in the global atmosphere since 2002. In our work, for unraveling the roles of CFCs in global warming, we make three innovations: first, we take a truncated period of analysis from 1969 to 1998 when the concentration of CFCs in the atmosphere has been on the ascendency as well as the global temperature. For our analysis, we choose the growth in the cumulative level of CFCs ( r rcump) on earth's atmosphere from 1969 to 1998 as the relevant variable for measuring the concentration of CFCs in the atmosphere. Secondly, we consider the change in global temperature (cgt) as our dependent variable to capture global warming. Finally, we take two indicators of human economic activities, namely, growth in US GDP (grusgdp) and growth in the GDP of the rest of the world ( $g r r w g d p)$. Thus the variable grrwgdp is the growth in the global GDP less the US GDP, all expressed in 2005 constant prices. Note that GDP variables and concentration of CFCs are expressed in natural logarithms wherefrom we calculate the growth rates. The critical question for us is whether there exists any long-term relationship between cgt and grcump using the two growth variables (grrwgdp, grusgdp) as the controlled variables during 1969 to 1998.

\subsection{ARDL Modelling}

This section examines the relationship between the annual change in global temperature from the previous year (cgt) and growth in cumulated CFC pollution ( grcump) and other variables of anthropogenic significance over the period 1969 to 1998 for the globe. To begin the analysis we use the ARDL bounds testing approach to deal with problems of autocorrelation and non-stationarity of key variables. Given the importance of addressing problems of autocorrelation and non-stationarity in order to get reliable results, we use time series methods to investigate the short and long run dynamics of the relationship between some of the relevant variables. The method we use is the autoregressive distributed lag (ARDL) bounds testing approach of Pesaran et al. (2001) to testing for cointegration between CFCs pollution and other variables of interest. The ARDL approach involves two steps.

- Step 1 tests for the existence of a long-run relationship between the variables of interest as predicted by the theory.

- If such a relationship is shown to exist, then Step 2 estimates the short and long run parameters of the relationship.

We begin by verifying that none of our variables of interest are integrated of order greater than 1 . We present some of the relevant results in Table 1. Our statistical tests indicate the presence of a unit root in some variables but there is no variable that is integrated of order greater than 1 (one). Thus, all our variables of interest used in the research are either I(0) or I(1) and hence appropriate for application of the ARDL bounds testing methodology. Our postulated model for ARDL bounds testing is written as:

$$
\begin{gathered}
\Delta c g t_{t}=\alpha_{0}+\rho c g t_{t-1}+\operatorname{aop}_{t-1}+\tau w_{t-1}+\sum_{i=1}^{p-1} \alpha_{i} \Delta y_{t-i}+\sum_{i=0}^{q-1} b_{i} \Delta o p_{t-i}+\omega_{t} \\
\Delta c g t_{t}=\alpha_{0}+\rho c g t_{t-1}+a o p_{t-1}+\tau w_{t-1}+\sum_{i=1}^{p-1} \alpha_{i} \Delta y_{t-i}+\sum_{i=0}^{q-1} b_{i} \Delta o p_{t-i}+\omega_{t}+\mu \sum \Delta \mathrm{w}_{t-j}
\end{gathered}
$$

Where $y$ is the dependent variable (cgt); $o p$ is the independent variable of CFCs pollution (grcump); $w$ is a vector of other deterministic variables of anthropogenic causes (grusgdp and grrwgdp) and $\omega_{t}$ is an iid stochastic process. Ignoring the time subscript $t$, we will explain them in the data section. The symbol $\Delta$ labels the first difference of a variable. We posit that the two variables $y$ and $o p$ in eq. (1a) are not cointegrated if $\rho=$ $a=0$. Pesaran et al. (2001) have proposed the F-test to test the presence of cointegration in the estimated ARDL model. The decision is based on two critical bounds: the upper and the lower one. When the F-statistic is greater than the upper bound the null hypothesis is rejected. This means that there is a long run relationship between $y$ and $o p$. Note that Equation (1b) is an extension of Equation (1a) with the additional term to incorporate $\Delta w_{t}$.

The ARDL model in equation (1a) assumes a linear combination of $y$ and $o p$ which indicate a symmetric adjustment in the long and the short run of dependent variable to any shock in $o p$ - our variable of interest. Note that our model is consistent with Pesaran et al. (2001) who have developed a linear cointegration autoregressive distributed lag model (ARDL) to evaluate simultaneously the long run and the short run effects. In their model the dependent variable $\left(y_{t}\right)$ responds symmetrically to both increases and decreases in independent variable $\left(o p_{t}\right)$.

To do the above, we use the ARDL bounds testing approach of Pesaran et al (2001). The advantage of using this time series approach is that we do not need to worry about endogeneity between variables since coefficient estimates in the presence of cointegration have the superconsistency property, implying that endogeneity does 
not affect the results (Engle and Granger, 1987). The superconsistency property of the estimates holds even if there are omitted stationary variables (Herzer and Strulig, 2013). Step 1 of the ARDL approach involves estimating an unrestricted ARDL Error Correction Model (ECM), as shown in the generic model given by Equation (1a). The specific equations and their results are summarized in Table 2.

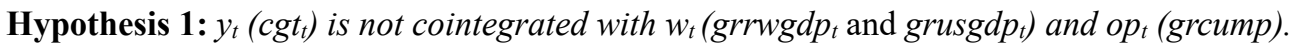

To do this, we use the ARDL bounds testing approach of Pesaran et al (2001). The advantage of using this time series approach is that we do not need to pay any attention to the endogeneity between variables since coefficient estimates in the presence of cointegration have the superconsistency property, implying that endogeneity does not affect the results (Engle and Granger 1987). The superconsistency property of the estimates holds even if there are omitted stationary variables (Herzer and Strulig, 2013).

\subsection{Data}

Our data from 1969 to 1998 came from three sources. First, we have used the global GDP and the US GDP data (constant at 2005 prices) from the national accounts data of the World Bank. Secondly, the global temperature data came from the NOAA (National Oceanic and Atmospheric Administration) data set in centigrade. Finally, the CFCs data in thousand metric tons came from the internet source, "Alternative Fluorocarbons Environmental Acceptability Study Production, Sales and Atmospheric Release of Fluorocarbons". All variables, except the temperature data, are expressed in national logarithms wherefrom their growth rates are extracted. The summary statistics are provided in Appendix 1. We present the unit root results in Table 1.

Table 1. Variables of Interests and their Basic Time Series Properties

\begin{tabular}{lccc}
\hline Variables & Order of Integration & Phillips-Perron $(\mathbf{Z}(\mathbf{t}))$ & $\mathbf{5 \%}$ Critical Value \\
\hline cgt & $\mathrm{I}(0)$ & -4.36 & -3.58 \\
grcump & $\mathrm{I}(1)$ & $-3.63^{*}$ & -3.58 \\
grrwgdp & $\mathrm{I}(1)$ & $-5.78^{*}$ & -3.58 \\
grusgdp & $\mathrm{I}(0)$ & -4.19 & -3.58 \\
\hline
\end{tabular}

Note: * implies the result is for the first difference of the relevant variable. In Table 1 we present the unit root results for the Phillips-Perron test. In an additional document we provide Dickey-Fuller test results confirming that there is no variable in our system that is integrated of order 2 or more.

In Figure 1 we plot the time profile of each variable of interest. There are some interesting pictures emerging from observation: first, we note that the change in global temperature (cgt) shows a distinct upward trend during 1969-1998, though the path is uneven with many sharp ups and downs. All other variables display downward trends and some fluctuations along their paths.

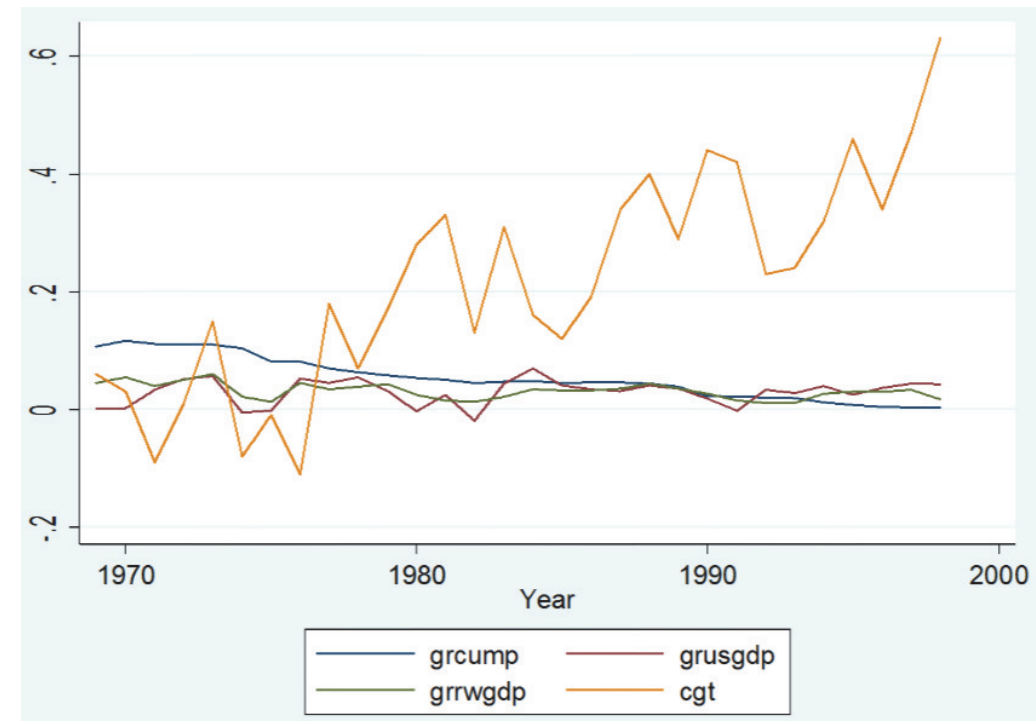

Figure 1. Time Profiles of Variables of Interest 
In the following sub-section we provide the results from the time series analysis of the dynamic paths of the variables. Because the data on cgt shows a clear upward trend, we use the trend option with the Dickey-Fuller test and the Phillips-Perron test to include a constant and time trend in the augmented regressions. The augmented regression establishes that $c g t$ is an $\mathrm{I}(0)$ variable once we take the trend option (see the additional materials).

\subsection{Results}

In Table 2 we present the ARDL and ECM results. Ignoring the actual values of the coefficients, in all models the coefficients of growth in CFCs pollution ( $\mathrm{grcusm}$ ) are negatively correlated with change in global temperature $(c g t)$ and they are all statistically significant $1 \%$ level of significance. However, there exists a stable long run relationship at the 5\% level of significance. Secondly, none of the growth in GDP variables has unambiguous effects or statistical significance in Model 2 and Model 3. Only in Model 1 we note that the growth in GDP of the rest of the world ( grrwgdp) increases the growth in the concentration of CFCs ( $g r c u m p$ ) in the atmosphere. Interestingly, the growth in US GDP (grusgdp) lowers grcump. In Model 1, both these effects of GDP on cgt are statistically significant. However, the role of growth in GDP on the global warming is not supported in Model 2 and Model 3. Note that our Model(1) is given by equation (1b) while Model (2) and Model (3) by equation (1a). As expected, there are some subtle changes in results across models as discussed below.

An interesting case arises when we compare Model 1 with Model 2 and Model 3: Model 2 and Model 3 have more meaningful error correction models due to the statistically significant relationships in first or second differences in all the variables, which provides evidence of short-run causation. There is thus evidence of causality from the error correction term. In Model 1, there is no such evidence of causality. It is also important to note that for all models, the F Statistic establishes a stable long-run relationship between $c g t$ and other variables of interests at $5 \%$ level of significance. It is also important to note that the statistically significant error correction term suggests long run causation in the Granger sense. But there is evidence of over correction in Model 1 from temporary shocks. We don't see this over-correction for Model 2 and Model 3. The statistical significance of the ECM coefficient for each model indicates the existence of a highly stable long-run relationship.

Table 2. Regression Results for ARDL and ECM Models

\begin{tabular}{|c|c|c|c|}
\hline Variable & Model (1) ${ }^{\text {S\$ }}$ & Model (2) $)^{\$ S}$ & Model (3) $)^{\$ S}$ \\
\hline Independent Variable & $\Delta \operatorname{cgt}_{t}$ & $\Delta \operatorname{cgt}_{t}$ & $\Delta \operatorname{cgt}_{t}$ \\
\hline \multicolumn{4}{|l|}{ Adjustment } \\
\hline$c g t_{t-1}$ & $-1.01 * * *$ & $-0.81 * * *$ & $-0.79 * *$ \\
\hline \multicolumn{4}{|l|}{ LONR-RUN } \\
\hline grcump $_{t-1}$ & $-6.19 * * *$ & $-4.71 * * *$ & $-5.04 * * *$ \\
\hline$g r r w g d p_{t-1}$ & $12.75^{* *}$ & & 2.24 \\
\hline $\operatorname{grusgdp}_{t-1}$ & $-5.72 *$ & 0.55 & \\
\hline \multicolumn{4}{|l|}{ SHORT-RUN } \\
\hline$\Delta g r r w g d p_{t-1}$ & $12.75^{* *}$ & & \\
\hline$\Delta g r u s g d p_{t-1}$ & $-05.72 * *$ & & \\
\hline CONSTANT & $0.32 * *$ & $0.36^{* *}$ & $0.22 * *$ \\
\hline No of obs & 26 & 26 & 26 \\
\hline Adj R squared $\$$ & 0.52 & 0.33 & 0.33 \\
\hline F statistic for no cointegration & $8.05 * * *$ & $5.13 * *$ & $5.63 * *$ \\
\hline Cointegration & Yes & Yes & Yes \\
\hline
\end{tabular}

Note: $* * *: 1 \%, * *: 95 \%, *: 90 \%$. \$: Note that all variables have been transformed - including the dependent variable, like logging and differencing. All these transformations have changed the variance and also the units in which variance is measured. As a result, the choice of transformation explains much of the variance. Since $\mathrm{R}^{2}$ refers to the fraction of variance explained by a model, an $\mathrm{R}^{2}$ greater than $25 \%$ is the benchmark for a good regression in a time series analysis with transformation of variables. \$\$: The software Stata reports the t-statistic since the number of observations is less than 30 and the population has an unknown standard deviation (see the Stata output attached to the submission).

\section{Concluding Comments}

Is there any empirical evidence from the vantage point of time series analysis that CFCs cause global warming 
since the 1970s? We apply the standard tools of ARDL modelling to answer the question as Gangopadhyay and Nilekantan (2017) and Akhtar and Alexander (2016) have recently exploited the ARDL methodology for various time series models. From the three parsimonious models tested in this paper we find no evidence of CFCs causing rapid rise in global temperature, or global warming, though they bear a meaningful long-term relationship with the change in global temperature during 1969-1998. As a counter-intuitive finding, we note that the growth in CFCs seems to cause a decline in the increases in the global temperature. It is true that CFCs deplete the ozone layer, but in-depth statistical analysis shows that the growth in CFCs do not increase the rate of global warming, rather CFCs seem to have caused a decline in the rate of global warming. A more nuanced and regional analysis will be necessary to fully understand the complete role of CFCs and global warming.

\section{References}

Anwar, S., \& Alexander, R. J. (2016). Pollution, energy use, GDP and trade: Estimating the long-run relationship. Applied Economics, 48(35), 3277-3292, Published online 5 May 2016. https://doi.org/10.1080/00036846.2016

Chang, C. (2010). A multivariate causality test of carbon dioxide emissions, energy consumption and economic growth in China. Applied Energy, 87, 3533-3537. https://doi.org/10.1016/j.apenergy.2010.05.004

Chen, W. J. (2012). The relationships of carbon dioxide emissions and income in a newly industrialized economy. Applied Economics, 44(13), 1621-1630. https://doi.org/10.1080/00036846.2010.548786

Dang, T. D., Mahanty, S., \& Mackay, S. (2013a). Living with pollution. Critical Asian Studies, 45(4), 643-669. https://doi.org/10.1080/14672715.2013.851163

Dang, V. et al. (2013b). Economic Development, Inequality and Climate Change in Vietnam, Munich: Munich Personal RePEc Archive (MRPA). Retrieved from http://mpra.ub.uni-muenchen.de/54190/

Dong, B., Gong, J. \& Zhao, X. (2012). FDI and environmental regulation: pollution haven or a race to the top. Journal of Regulatory Economics, 41(2), 216-237. https://doi.org/10.10.1007/s11149-011-9162-3

Engle, R. F. (1982). Auto regressive conditional heteroskedasticity with estimates of the variance of United Kingdom inflation. Econometrica, 50, 987-1007. https://doi.org/10.2307/1912773

Engle, R. F., \& Granger, C. W. J. (1987). Cointegration and error correction: Representation, estimation and testing," Econometrica, 55, 251-276. https://doi.org/10.2307/1913236

Gangopadhyay, P., \& Nilekantan, R. (2017). Collective Violence and Climate: A Quantitative Analysis of the Indian Case. Journal of Development Studies, Published online 5 January 2017. https://doi.org/10.1080/00220388.2016.1269890

Granger, C. W. J. (1981). Cointegrating Variables and Error Correcting Models. Working Paper, University of California, San Diego, California. https://doi.org/10.1016/0304-4076

Herzer, D., \& Strulig, H. (2013). Religiosity and Income: A Panel Cointegration and Causality Analysis. Center for European Governance and Economic Development Research Discussion Paper No.168 - August 2013.

$\mathrm{Lu}$, Q. B. (2013). Cosmic ray-driven reaction and greenhouse effect of halogenated molecules: Culprits for atmospheric ozone depletion and global climate change. International Journal of Modern Physics B, 279(17), 1-38. https://doi.org/10.1142/S0217979213500732

Pesaran, M. H., Shin, Y., \& Smith, R. J. (2001). Bounds Testing Approaches to the Analysis of Level Relationships." Journal of Applied Econometrics, 16, 289-326. https://doi.org/10.1002/jae.616

Romilly, P., Song, H., \& Liu, X. (2001). Car ownership and use in Britain: a comparison of the empirical results of alternative cointegration estimation methods and forecasts. Applied Economics, 33(14), 1803-1818. https://doi.org/10.1080/00036840011021708

Tang, X. (2015). Testing the pollution haven effect: Does the type of FDI matter? Environmental and Resource Economics, 60(2), 549-578. https://doi.org/10.1007/s10640-014-9779-7

Tingvall, P., \& Ljungwall, C. (2012). Is China different? A meta-analyis of export-led growth. Economics Letters, 115(2), 177-179. https://doi.org/10.1016/j.econlet.2011.11.028

Toda, H. Y., \& T. Yamamoto. (1995). Statistical Inferences in Vector Autoregressions with Possibly Integrated Processes. Journal of Econometrics, 66, 225-250. https://doi.org/10.1016/0304-4076(94)01616-8

Wang, S. S., Zhou, D. Q. Z. P., \& Wang, Q. W. (2011). CO2 emissions, energy consumption and economic growth in China: A panel data analysis. Energy Policy, 39(2), 4870-4875. 
https://doi.org/10.1016/j.enpol.2011.06.032

Zhang, J., \& Gangopadhyay, P. (2015). Dynamics of environmental quality and economic development: Regional experience from the Yangtze River delta of China. Applied Economics, 47(29), 3113-3123. https://doi.org/10.1080/00036846.2015.1011324

Zhang, X. P., \& Cheng, X. M. (2009). Energy consumption, carbon emissions and economic growth in China. Ecological Economics, 68(10), 2706-2712. https://doi.org/10.1016/j.ecolecon.2009.05.011

\section{Appendix 1.}

Table 3. Summary Statistics of Variables of Interest

\begin{tabular}{lcllll}
\hline Variable & Observations & Mean & Std. Dev. & Min. & Max \\
\hline Cgt & 30 & 0.21 & 0.18 & -0.11 & 0.63 \\
Grcump & 30 & 0.052 & 0.03 & 0.003 & 0.03 \\
Grusgdp & 30 & 0.030 & .01 & 0.004 & 0.01 \\
Grrwgdp & 30 & 0.029 & 0.02 & -0.019 & 0.02 \\
\hline
\end{tabular}

Source: Constructed by the authors by using the econometric software Stata.

\section{Notes}

Note 1. Lu (2013) claimed a link between chlorofluorocarbons (CFC) in the atmosphere and global warming. According to this work "banned aerosols" and not carbon dioxide were "responsible for global warming since the 1970s". The work also predicted that global temperatures would fall as the concentration of CFC in the atmosphere has been declining since the 1990s.

Note 2. The standard rebuttal to $\mathrm{Lu}$ (2013) is as follows: global temperatures have continued to rise even though the concentration of CFCs in the atmosphere has stopped rising since 1990s. Many critics argue that despite the stabilization of CFCs since the 1990s, troposphere temperatures have continued to grow by approximately $0.3^{\circ} \mathrm{C}$. To obviate this debate, in this work, we choose the period from 1969-1998 when both the CFCs and the global temperatures have risen to detect any long-term relationship between CFCs and global warming.

\section{Copyrights}

Copyright for this article is retained by the author(s), with first publication rights granted to the journal.

This is an open-access article distributed under the terms and conditions of the Creative Commons Attribution license (http://creativecommons.org/licenses/by/4.0/). 